\title{
Cognitive-behavioural therapy for depression in people with a somatic disease: meta-analysis of randomised controlled trials
}

\author{
Matthijs W. Beltman, Richard C. Oude Voshaar and Anne E. Speckens
}

\section{Background}

Meta-analyses on psychological treatment for depression in individuals with a somatic disease are limited to specific underlying somatic diseases, thereby neglecting the generalisability of the interventions.

\section{Aims \\ To examine the effectiveness of cognitive-behavioural therapy (CBT) for depression in people with a diversity of somatic diseases.}

\section{Method}

Meta-analysis of randomised controlled trials evaluating CBT for depression in people with a somatic disease. Severity of depressive symptoms was pooled using the standardised mean difference (SMD).

\section{Results}

Twenty-nine papers met inclusion criteria. Cognitivebehavioural therapy was superior to control conditions with larger effects in studies restricted to participants with depressive disorder $(\mathrm{SMD}=-0.83,95 \% \mathrm{Cl}-1.36$ to -0.31 , $P<0.001)$ than in studies of participants with depressive symptoms (SMD $=-0.16,95 \% \mathrm{Cl}-0.27$ to $-0.06, P=0.001$ ). subgroup analyses showed that CBT was not superior to other psychotherapies.

\section{Conclusions}

Cognitive-behavioural therapy significantly reduces depressive symptoms in people with a somatic disease, especially in those who meet the criteria for a depressive disorder.

\section{Declaration of interest}

None.

We conducted a meta-analysis of the effectiveness of CBT for Major depression occurs in $6-14 \%$ of medical in-patients, ${ }^{1}$ with even higher percentages in specific populations such as people with type 1 or type 2 diabetes $^{2}$ or cancer. ${ }^{3}$ Irrespective of the underlying somatic disease, depression always dramatically decreases quality of life. In medical and surgical in-patients, depressive symptoms are associated with longer hospital stays, higher rates of rehospitalisation and increased hospital utilisation. ${ }^{4,5}$ In out-patients with chronic medical conditions such as diabetes and heart disease, comorbid depressive disorder has been associated with increased medical consumption, amplification of somatic symptoms and disability, poor self-care and adherence to treatment, and increased morbidity and mortality. ${ }^{6}$ Although both pharmacological and psychological therapy are effective for depressive disorder in the general population, ${ }^{7}$ studies in individuals with somatic diseases have yielded mixed results. ${ }^{8,9}$ As antidepressant medication may interfere with somatic diseases or their treatment, leading to high drop-out rates, ${ }^{10}$ psychological treatments might be more suitable in this population. Therefore, it is not surprising that in the past decades a considerable number of studies have focused on the psychological treatment of depression in people with a somatic disease. ${ }^{10-16}$ Recent meta-analyses on psychological treatment for depression in individuals with somatic diseases, however, were limited for the following reasons. First, previous meta-analyses focused on the treatment of depressive symptoms in people with specific somatic diseases such as cancer, rheumatoid arthritis or multiple sclerosis. However, as depressive symptoms occur in a variety of somatic diseases, this approach limits our knowledge about the generalisability of cognitive-behavioural therapy (CBT). Secondly, most meta-analyses included a wide range of psychological interventions, ${ }^{10,12-16}$ which might have diluted the effect of CBT, and CBT has been shown by previous research to be one of the most effective interventions for depression. ${ }^{17,18}$ Finally, none of these meta-analyses applied the diagnostic criteria of depressive disorder as an inclusion criterion. depression in people with an underlying somatic disease. As we hypothesised that we would find higher efficacy in people who met predefined criteria for depression, we conducted separate meta-analyses for studies restricted to participants with depressive disorder and from those with depressive symptoms.

\section{Method}

To identify relevant studies, we conducted a search of the Cochrane Central Register of Controlled Trials, PubMed and PsycINFO up to October 2008. We used the text keywords depressive disorder, depression, major depressive disorder or depressive sympto* combined with the keywords psychotherapy, cognitive therapy, behavi* therapy or CBT. We did not include any terms related to underlying somatic diseases to prevent the exclusion of any possible relevant study. This search strategy was repeated using the MESH-terms depressive disorder (exploded), depression (exploded), depressive disorder, major (exploded) AND psychotherapy (exploded), limited to humans, clinical trial or randomised controlled trial. Articles were retrieved for further assessment if the title or abstract suggested that a CBT (broadly defined) was used in a population with a somatic disease. Subsequently, the search was extended by a manual search of the reference lists of all resulting randomised controlled trials (RCTs).

\section{Inclusion criteria}

Manuscripts were included if they met the following criteria:

(a) use of a randomised controlled research design;

(b) inclusion of participants with an underlying somatic disease;

\section{Identification of studies}


(c) inclusion of a treatment arm with CBT, defined as a protocolbased psychological treatment including at least cognitive restructuring and behavioural activation procedures for depression for a minimum of six sessions. We also included problem-solving therapy and cognitive-behavioural stress management on the prerequisite that these interventions met our definition of CBT;

(d) results for depressive symptoms were presented separately for each treatment arm at pre- and post-treatment;

(e) use of a valid outcome measure (validated self-report questionnaire or clinical interview).

The first two authors (M.W.B. and R.C.O.V.) independently checked the inclusion and exclusion criteria of the identified studies. Disagreement over inclusion was resolved through discussion. When no consensus could be reached, a third investigator (A.E.S.) decided. Excluded were outcome studies without a randomised controlled design (e.g. open trials, case series and case reports), review papers, studies examining depression associated with unexplained somatic symptoms (e.g. fibromyalgia, chronic fatigue syndrome, irritable bowel syndrome, chronic pain), studies of individuals aged 18 years and under, studies in which the CBT could not be distinguished from other elements of the intervention (e.g. depression care management), studies including people with dementia or severe cognitive impairment, and studies limited to a specific psychiatric disorder with depressive symptoms as a second outcome measure. The language of publication was not an exclusion criteria.

\section{Data extraction, selection procedure and quality assessment}

The first two authors subsequently coded the selected studies separately on a coding form consisting of the following items: year of publication, total number of patients included, number of completers and number who dropped out, underlying somatic disease, setting (in- or out-patient clinic), age, gender, type of CBT intervention, delivery of treatment (face-to-face, telephone, internet), individual or group treatment, number of sessions, type of control condition (classified as either treatment as usual, a waiting list or other psychotherapy), outcome measures, whether depressive symptoms were the primary or secondary outcome measure, completer or intent-to-treat analysis, the results on post-treatment measures of interest (see Statistical analysis), and finally the psychiatric diagnostic criteria used at the time of inclusion (depressive disorder or depressive symptoms). Depressive disorder was defined as meeting DSM-IV ${ }^{19}$ criteria or scoring above a predefined cut-off level on a screening questionnaire for depression. Depressive symptoms were used to indicate the dimensional score on a self-report questionnaire for depressive symptoms. Discrepancies in the two coding forms were resolved by discussion between both authors (M.W.B. and R.C.O.V.), and when no consensus could be reached the third author decided (A.E.S.).

When data on means, standard deviations or number of participants in the experimental or control groups at the end of the treatment were missing, we contacted the trial authors. Where standard deviations were not available from trial authors, they were calculated from $t$-tests, confidence intervals or standard errors, where reported in articles. ${ }^{20,21}$ If these additional data were not available, the study data were not included in the meta-analysis.

The methodological quality of the included studies was assessed using the Amsterdam-Maastricht consensus list ranging from 0 (poor quality) to 19 (excellent quality). The
Amsterdam-Maastricht consensus list is accepted by the Cochrane Review Group ${ }^{22}$ and has been used previously in systematic reviews of RCTs in psychiatric disorders. ${ }^{23,24}$ It covers the Chalmers criteria usually applied in the assessment of study quality. $^{22,25}$

\section{Statistical analysis}

For the main analyses, studies were subdivided in studies restricted to participants with depressive disorder according to predefined criteria and studies of participants with depressive symptoms. The primary outcome measure for both categories was the severity of depressive symptoms. We a priori decided to use the Beck Depression Inventory (BDI ${ }^{26}$ or Beck Depression Inventory-II (BDI-II $)^{27}$ as the primary outcome measure and, if not available (in order of preference), the Hamilton Depression Rating Scale (HDRS $)^{28}$ or the Center for Epidemiological Studies - Depression Scale (CES-D) ${ }^{29}$ If a separate measure of depressive symptoms was lacking, a subscale of a validated generic psychiatric instrument was used (in order of preference): the depression subscale of the Hospital Anxiety and Depression Scale (HADS), ${ }^{30}$ the Profile of Mood Symptoms (POMS), ${ }^{31}$ the Symptom Checklist 90 -item version (SCL-90-R) ${ }^{32}$ or the Impact of Rheumatic Diseases on Health and Lifestyle (IRGL). ${ }^{33}$

Data were analysed with Review Manager (RevMan) version 5.0.17 for Windows. At the moment, Cochrane methodology is widely advised and accepted as the preferred method in metaanalytic studies. We used the standardised mean difference (SMD) as the summary statistic in our meta-analysis, which expresses the size of the treatment effect in each trial relative to the variability observed in that trial, enabling us to pool different scales assessing one outcome measure. The SMD thus reflects the difference in the mean outcome between groups divided by the standard deviation of outcomes among participants. We applied the chi-squared test for heterogeneity. Since the chi-squared test has low power to assess heterogeneity where a small number of participants or trials are included, the $P$-value was conservatively set at $0.10 .^{34}$ We used a fixed-effects model if homogeneity was found and a random-effects model if not (although the latter model slightly compromised the statistical power of our analysis). Summary statistics were based on intention-to-treat data and when missing, on available case analyses. It is generally assumed to be more realistic to include papers based on their completer data than excluding papers by not providing intention-to-treat data, on the prerequisite that potential difference between studies will be discussed and taken into account as a source of heterogeneity. ${ }^{34}$

The following subgroup analyses were performed to examine whether specific characteristics of the studies were related to the effect sizes:

(a) type of CBT condition, classified as classic CBT, problemsolving therapy and cognitive-behavioural stress management;

(b) control condition, classified as treatment as usual, waiting-list control condition and other psychotherapy;

(c) treatment delivery in group versus individual format.

Sensitivity analyses were undertaken to assess whether the quality of the studies was related to the magnitude of the observed effect sizes. Studies were limited to those of higher quality as determined by risk of: drop-out rate lower than $20 \%$, studies providing intention-to-treat data, outcome assessment by validated questionnaire (excluding subscales) or whether depressive symptoms was the primary or secondary outcome measure. Publication bias was explored by preparing funnel plots for all outcome measures. 


\section{Results}

\section{Search strategy}

The study extraction and selection process as recommended by the Quality of Reporting of Meta-analyses (QUOROM) statement ${ }^{35}$ is shown in Fig. 1. The initial search yielded 1361 reference titles in PubMed, 2677 in PsycINFO and 604 in the Cochrane Library of which 305 titles were identified as having a possible relevance to the treatment of depression in people with an underlying somatic disease by M.W.B. or R.C.O.V. After screening of the abstracts and the full text, we excluded 266 papers. Of the 39 articles of interest, 13 papers did not provide sufficient information for the metaanalyses and we contacted the corresponding author for this. Of the 13 authors contacted, ${ }^{2,36-47} 3$ authors responded to our request and were included. ${ }^{42,44,45}$ Two authors claimed that the relevant study data were not available anymore $e^{36,38}$ and 8 authors did not respond to our request, leaving 29 studies for the meta-analysis. $^{42,44,45,48-73}$

\section{Study quality}

Online Tables DS1 and DS2 list the scores for methodological quality of the studies as assessed with the Amsterdam-Maastricht

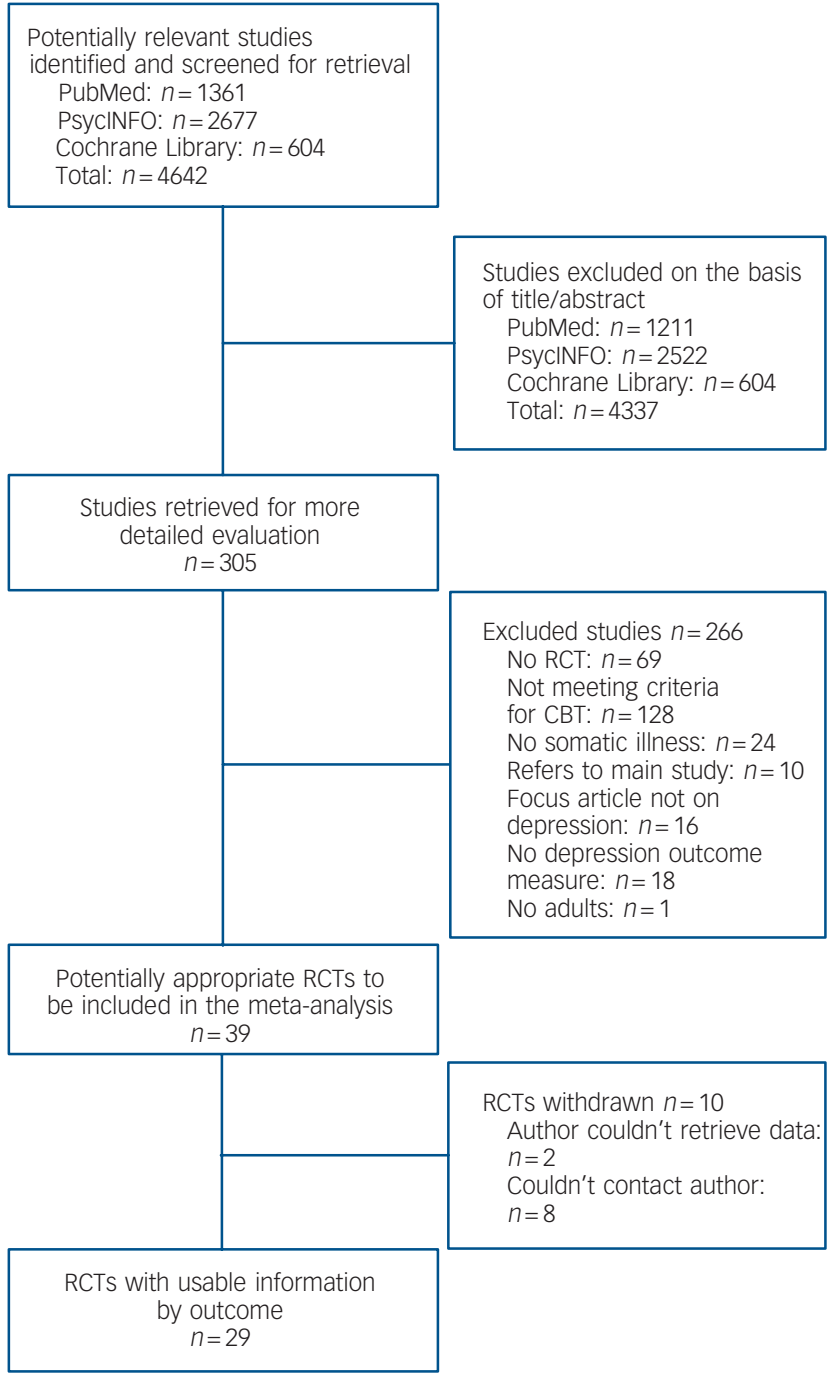

Fig. 1 Flow diagram of randomised controlled trials (RCTs) included and excluded in meta-analysis. CBT, cognitivebehavioural therapy. consensus list. The sum score (range 0-19) is taken to reflect study quality but as neither participants nor therapists can be masked to a psychological treatment condition, the maximum score in psychotherapy studies is 17 . Interrater discrepancies were limited to a one-point difference in eight studies and a two-point difference in two studies. The broad range from 8 to 16 indicates a high variation of study quality, which emphasises the need for the (planned) sensitivity analyses to evaluate the effect of the most important issues of study quality.

\section{Study characteristics}

The study characteristics are summarised in Table 1 for studies restricted to individuals with depressive disorder and Table 2 for studies of individuals with depressive symptoms. The 13 trials that included participants with depressive disorder $^{44,48,51,52,55,57,58,63,66,68,69,72,73}$ comprised a total of 1139 people with a mean age of 51 years. These studies all had treatment of depression as their primary goal. In total, 252 participants (22\%) dropped out prematurely; $112(21 \%)$ in the CBT condition and $140(23 \%)$ in the control condition $\left(\chi^{2}=0.62\right.$, d.f. $\left.=1, P=0.43\right)$.

The 16 trials including participants with depressive symptoms ${ }^{42,45,49,50,53,54,56,59-62,64,65,67,70,71}$ included 1861 people with a mean age of 51 years. A total of 370 participants $(20 \%)$ dropped out before the outcome assessment; 192 (21\%) in the CBT condition and $178(19 \%)$ in the control condition $\left(\chi^{2}=0.93\right.$, d.f. $\left.=1, P=0.34\right)$. In six $(38 \%)$ of these studies the treatment of depressive symptoms was the primary goal $^{42,45,56,60,70,71}$ and in $10 \quad(62 \%)$ a secondary aim. ${ }^{49,50,53,54,59,61,62,64,65,67}$

Underlying somatic diseases in the different studies were: cancer $(n=8)$, HIV infection $(n=6)$, multiple sclerosis $(n=5)$, rheumatoid arthritis $(n=3)$, vascular disease $(n=3)$, diabetes mellitus $(n=1)$, chronic obstructive pulmonary disease $(n=1)$, chronic renal failure $(n=1)$ and various somatic diseases $(n=1)$.

Six studies ${ }^{44,51-53,55,64}$ compared an active treatment with two control conditions (e.g. an attention control, as well as a standard care group). We combined data from these control conditions and compared this with data for the treatment group. In the subgroup analysis of the control condition we used both control conditions separately. One study ${ }^{63}$ compared two active treatments (problemsolving therapy and problem-solving therapy with a significant other) with a waiting-list control condition. In this case we combined the two treatment conditions and compared this with the control condition.

Most studies evaluated a classic CBT intervention, five studies evaluated cognitive-behavioural stress management, ${ }^{54,60,64,67,71}$ and two studies problem-solving therapy ${ }^{63,69}$ (all studies fulfilling our inclusion criteria for CBT). The number of treatment sessions ranged from 6 to 20 weeks, delivered either in a group format (16 studies) or individually (13 studies). In two studies, the intervention was delivered exclusively by telephone. ${ }^{57,66}$

\section{Meta-analyses}

The results for the primary outcome variable are presented in Fig. 2 for studies of individuals with depressive disorder and Fig. 3 for studies of individuals with depressive symptoms. Because of significant heterogeneity in the studies restricted to participants with depressive disorder $\left(\chi^{2}=170.12\right.$, d.f. $=12$, $P<0.001, I^{2}=93 \%$ ), we used a random-effects model. We found a significant pooled standardised mean difference of $-0.83(95 \%$ CI -1.36 to -0.31$)$ in favour of the CBT condition $(Z=3.13$, $P=0.002)$. Inspection of the data showed that the heterogeneity 
Table 1 Study characteristics of participants with depressive disorder

\begin{tabular}{|c|c|c|c|c|c|c|c|c|c|c|}
\hline Study & $\begin{array}{c}\text { Included, } \\
n\end{array}$ & $\begin{array}{c}\text { Dropped out, } \\
n(\%)\end{array}$ & $\begin{array}{c}\text { Completers, } \\
n\end{array}$ & $\begin{array}{l}\text { Age, years: } \\
\text { mean }\end{array}$ & $\begin{array}{c}\text { Male, } \\
\%\end{array}$ & Somatic disease & $\begin{array}{c}\text { Sessions, } \\
n\end{array}$ & $\begin{array}{l}\text { Group } \\
\text { therapy }\end{array}$ & $\begin{array}{l}\text { Control } \\
\text { condition(s) }\end{array}$ & Setting \\
\hline Larcombe $(1984)^{48}$ & 21 & $2(10)$ & 19 & 43 & 32 & Multiple sclerosis & 6 & Yes & WLC & Out-patients \\
\hline Kelly $(1993)^{51}$ & 115 & $47(41)$ & 68 & 34 & 100 & HIV & 8 & Yes & TAU and OP & Out-patients \\
\hline Evans $(1995)^{52}$ & 78 & $6(8)$ & 72 & 54 & 65 & Cancer & 8 & Yes & TAU and OP & Out-patients \\
\hline Markowitz $(1998)^{55}$ & 75 & $23(31)$ & 52 & 37 & 83 & HIV & 16 & No & OP & Out-patients \\
\hline Mohr $(2000)^{57}$ & 32 & $9(28)$ & 23 & 42 & 28 & Multiple sclerosis & 8 & No & TAU & Out-patients \\
\hline Mohr $(2001)^{58}$ & 42 & $3(7)$ & 39 & 44 & 27 & Multiple sclerosis & 16 & No & $\mathrm{OP}$ & Out-patients \\
\hline Lincoln $(2003)^{44}$ & 123 & $5(4)$ & 118 & 66 & 51 & Heart disease & 10 & No & TAU and OP & In-patients \\
\hline Nezu $(2003)^{63}$ & 150 & $18(12)$ & 132 & 47 & 33 & Cancer & 10 & No & WLC & In-patients \\
\hline Mohr $(2005)^{66}$ & 127 & $5(4)$ & 122 & 48 & 23 & Multiple sclerosis & 16 & No & $\mathrm{OP}$ & Out-patients \\
\hline Savard $(2006)^{68}$ & 45 & $8(18)$ & 37 & 52 & 0 & Cancer & 8 & No & WLC & Out-patients \\
\hline Gellis $(2007)^{69}$ & 48 & $8(17)$ & 40 & 80 & 15 & Medically III & 6 & No & TAU & Out-patients \\
\hline Kunik $(2008)^{72}$ & 238 & $115(48)$ & 123 & 66 & 96 & COPD & 8 & Yes & $\mathrm{OP}$ & Out-patients \\
\hline Safren $(2008)^{73}$ & 45 & $3(7)$ & 42 & $n / a$ & $n / a$ & HIV & 12 & No & TAU & Out-patients \\
\hline Summary statistics & 1139 & $252(22)$ & 887 & 51 & & & & & & \\
\hline
\end{tabular}

\begin{tabular}{|c|c|c|c|c|c|c|c|c|c|c|}
\hline Study & $\begin{array}{c}\text { Included, } \\
n\end{array}$ & $\begin{array}{c}\text { Dropped out, } \\
n(\%)\end{array}$ & $\begin{array}{c}\text { Completers, } \\
n\end{array}$ & $\begin{array}{l}\text { Age, years: } \\
\text { mean }\end{array}$ & $\begin{array}{c}\text { Male, } \\
\%\end{array}$ & Somatic disease & $\begin{array}{c}\text { Sessions, } \\
n\end{array}$ & $\begin{array}{l}\text { Group } \\
\text { therapy }\end{array}$ & $\begin{array}{c}\text { Control } \\
\text { condition(s) }\end{array}$ & Setting \\
\hline Foley $(1987)^{49}$ & 41 & $5(12)$ & 36 & 39 & 15 & Multiple sclerosis & 6 & Yes & $\mathrm{OP}$ & Out-patients \\
\hline Greer $(1992)^{50}$ & 174 & $23(13)$ & 151 & 52 & 21 & Cancer & 6 & No & TAU & Out-patients \\
\hline Kraaimaat $(1995)^{53}$ & 77 & $6(8)$ & 71 & 57 & 32 & Rheumatoid arthritis & 10 & Yes & WLC and OP & Out-patients \\
\hline Henry $(1997)^{54}$ & 21 & $2(10)$ & 19 & 60 & 47 & Diabetes mellitus & 6 & Yes & WLC & Out-patients \\
\hline Edelman $(1999 a)^{42}$ & 119 & $27(23)$ & 92 & 50 & 0 & Cancer & 11 & Yes & TAU & Out-patients \\
\hline Edelman $(1999 b)^{56}$ & 60 & $13(22)$ & 47 & 48 & 0 & Cancer & 12 & Yes & $\mathrm{OP}$ & Out-patients \\
\hline Sharpe $(2001)^{59}$ & 53 & $8(15)$ & 45 & 55 & 29 & Rheumatoid arthritis & 8 & No & TAU & Out-patients \\
\hline Cruess $(2002)^{60}$ & 125 & $25(20)$ & 100 & 36 & 100 & HIV & 10 & Yes & WLC & Out-patients \\
\hline Evers $(2002)^{61}$ & 64 & $5(8)$ & 59 & 54 & 29 & Rheumatoid arthritis & 20 & No & TAU & Out-patients \\
\hline Kissane $(2003)^{62}$ & 303 & $24(8)$ & 279 & 46 & 0 & Cancer & 20 & Yes & $\mathrm{OP}$ & Out-patients \\
\hline Given $(2004)^{45}$ & 237 & $72(30)$ & 165 & $n / a$ & 20 & Cancer & 10 & No & TAU & Out-patients \\
\hline Blumenthal $(2005)^{64}$ & 134 & $10(7)$ & 124 & 63 & 69 & Heart disease & 16 & Yes & TAU and OP & Out-patients \\
\hline Chan $(2005)^{65}$ & 16 & $3(19)$ & 13 & 38 & 100 & HIV & 7 & Yes & WLC & Out-patients \\
\hline Antoni $(2006)^{67}$ & 130 & $52(40)$ & 78 & 50 & 100 & HIV & 10 & Yes & $\mathrm{OP}$ & Out-patients \\
\hline Lii $(2007)^{70}$ & 60 & $12(20)$ & 48 & $n / a$ & 48 & Renal failure & 8 & Yes & TAU & Out-patients \\
\hline Koertge $(2008)^{71}$ & 247 & 83 (34) & 164 & 62 & 0 & Heart disease & 20 & Yes & TAU & In-patients \\
\hline Summary statistics & 1861 & $370(20)$ & 1491 & 51 & & & & & & \\
\hline
\end{tabular}

of results could not be explained by the underlying somatic disease, but was caused by three positive outliers. ${ }^{48,63,69}$ Removal of these studies led to more homogeneous results, but reduced the effect size by -0.64 yielding a still significant pooled SMD of -0.19 ( $95 \%$ CI -0.33 to $-0.05, Z=2.69, P=0.007)$.

The studies of individuals with depressive symptoms yielded a smaller but still significant pooled SMD of -0.16 (95\% CI -0.27 to -0.06$)$ in favour of the CBT condition $(Z=3.19, P=0.001)$.

The funnel plots of both categories of papers were not suggestive of publication bias. The effect size was neither correlated with publication year nor with the quality score (all $P>0.22$ ). A strong correlation was found between publication year and quality score among studies restricted to participants with depressive disorder, showing an increase of study quality over the years (Spearman's rho $=0.67, \quad P=0.013)$. Based on Cochrane methodology, differences in quality score are addressed in sensitivity analyses as planned (see below) instead of excluding low-quality studies. We did not expect to find studies delivering CBT by telephone. This finding urged us to perform a post hoc subgroup analyses excluding these two studies, which yielded a higher effect size of $-0.92(95 \% \mathrm{CI}-1.55$ to -0.29$)$ in favour of the CBT condition $(Z=2.86, P=0.004)$ using a random-effects model.

Furthermore, the effect size was significantly correlated with the number of CBT sessions provided in the studies of participants with depressive symptoms (Spearman's rho $=0.53, P=0.033$ ), but not in the studies of participants with depressive disorder. In the studies of people with depressive symptoms, a post hoc subgroup analysis showed that the effect size in studies providing less than ten CBT sessions was -0.39 ( $95 \%$ CI -0.61 to -0.16$)$ in favour of the CBT condition $(Z=3.34, P=0.00008)$, compared with $-0.11(95 \%$ CI -0.22 to $0.00, Z=1.89, P=0.06)$ in studies providing ten or more sessions. 


\begin{tabular}{|c|c|c|c|c|c|c|c|c|c|c|c|c|}
\hline \multirow{4}{*}{ Study } & \multicolumn{3}{|c|}{ Experimental } & \multicolumn{2}{|c|}{ Control } & \multirow{2}{*}{\multicolumn{2}{|c|}{ Total Weight }} & \multirow{2}{*}{$\begin{array}{l}\text { Std mean difference } \\
\text { random, } 95 \% \mathrm{Cl}\end{array}$} & \multirow{2}{*}{\multicolumn{2}{|c|}{ Year }} & \multirow{2}{*}{\multicolumn{2}{|c|}{$\begin{array}{l}\text { Std mean difference } \\
\text { random } 95 \% \mathrm{Cl}\end{array}$}} \\
\hline & Mean & s.d. & Total & Mean & s.d. & & & & & & & \\
\hline & 8.11 & 5.04 & 9 & 33.4 & 9.72 & 10 & $5.3 \%$ & $-3.07(-4.49$ to -1.65$)$ & 1984 & $\leftarrow$ & & \\
\hline & 21.2 & 11.8 & 27 & 24.03 & 12.12 & 41 & $8.0 \%$ & $-0.23(-0.72$ to 0.25$)$ & 1993 & & & \\
\hline Evans, $1995^{52}$ & 20.9 & 11.7 & 27 & 23.1 & 12.04 & 45 & $8.1 \%$ & $-0.18(-0.66$ to 0.30$)$ & 1995 & & & \\
\hline Markowitz, $1998^{55}$ & 19.8 & 10.7 & 27 & 17.08 & 16.35 & 48 & $8.1 \%$ & $0.18(-0.29$ to 0.66$)$ & 1998 & & & \\
\hline Mohr, $2000^{57}$ & 18.7 & 13.8 & 16 & 26.7 & 13.7 & 16 & $7.5 \%$ & $-0.57(-1.28$ to 0.14$)$ & 2000 & & & \\
\hline Mohr, $2001^{58}$ & 12.9 & 8.6 & 20 & 18.9 & 12 & 19 & $7.6 \%$ & $-0.57(-1.21$ to 0.08$)$ & 2001 & & & \\
\hline Lincoln, $2003^{44}$ & 15.21 & 10.1 & 38 & 15.28 & 11.89 & 80 & $8.3 \%$ & $-0.01(-0.39$ to 0.38$)$ & 2003 & & & \\
\hline Nezu, $2003^{63}$ & 6.18 & 4.61 & 88 & 22.13 & 4.51 & 44 & $7.9 \%$ & $-3.46(-4.02$ to -2.91$)$ & 2003 & 4 & & \\
\hline Mohr, $2005^{66}$ & 15 & 10.83 & 60 & 18.48 & 10.28 & 62 & $8.3 \%$ & $-0.33(-0.69$ to 0.03$)$ & 2005 & & & \\
\hline Savard, $2006^{68}$ & 11.52 & 6.42 & 21 & 15.93 & 6.12 & 16 & $7.6 \%$ & $-0.69(-1.36$ to -0.01$)$ & 2006 & & & \\
\hline Gellis, $2007^{69}$ & 10.2 & 7.8 & 20 & 27.4 & 7.6 & 20 & $7.2 \%$ & $-2.19(-2.99$ to -1.39$)$ & 2007 & 4 & & \\
\hline Kunik, $2008^{72}$ & 14.19 & 13.69 & 118 & 14.54 & 13.47 & 120 & $8.5 \%$ & $-0.03(-0.28$ to 0.23$)$ & 2008 & & & \\
\hline Safren, $2008^{73}$ & 12.26 & 10.55 & 23 & 19.54 & 9.19 & 22 & $7.7 \%$ & $-0.72(-1.33$ to -0.12$)$ & 2008 & & & \\
\hline Total $(95 \% \mathrm{Cl})$ & & & 494 & & & 543 & $100.0 \%$ & $-0.83(-1.36$ to 0.31$)$ & & & & \\
\hline $\begin{array}{l}\text { Heterogeneity: } \tau^{2}= \\
\text { Test for overall eff }\end{array}$ & $\begin{array}{l}; x^{2}= \\
z=3.1\end{array}$ & $\begin{array}{l}12, \\
=0 . C\end{array}$ & & 0.0 & $1^{2}=$ & & & & & -2 & -1 & $\begin{array}{l}\begin{array}{l} \\
0\end{array} \\
\text { al } \\
\text { Favours control }\end{array}$ \\
\hline
\end{tabular}

Fig. 2 Forrest plot of standard mean difference (with 95\% Cl) of effect of cognitive-behavioural therapy on depressive symptoms in studies including participants with depressive disorder, with overall effect (black diamond), based on meta-analysis. Std, standard.

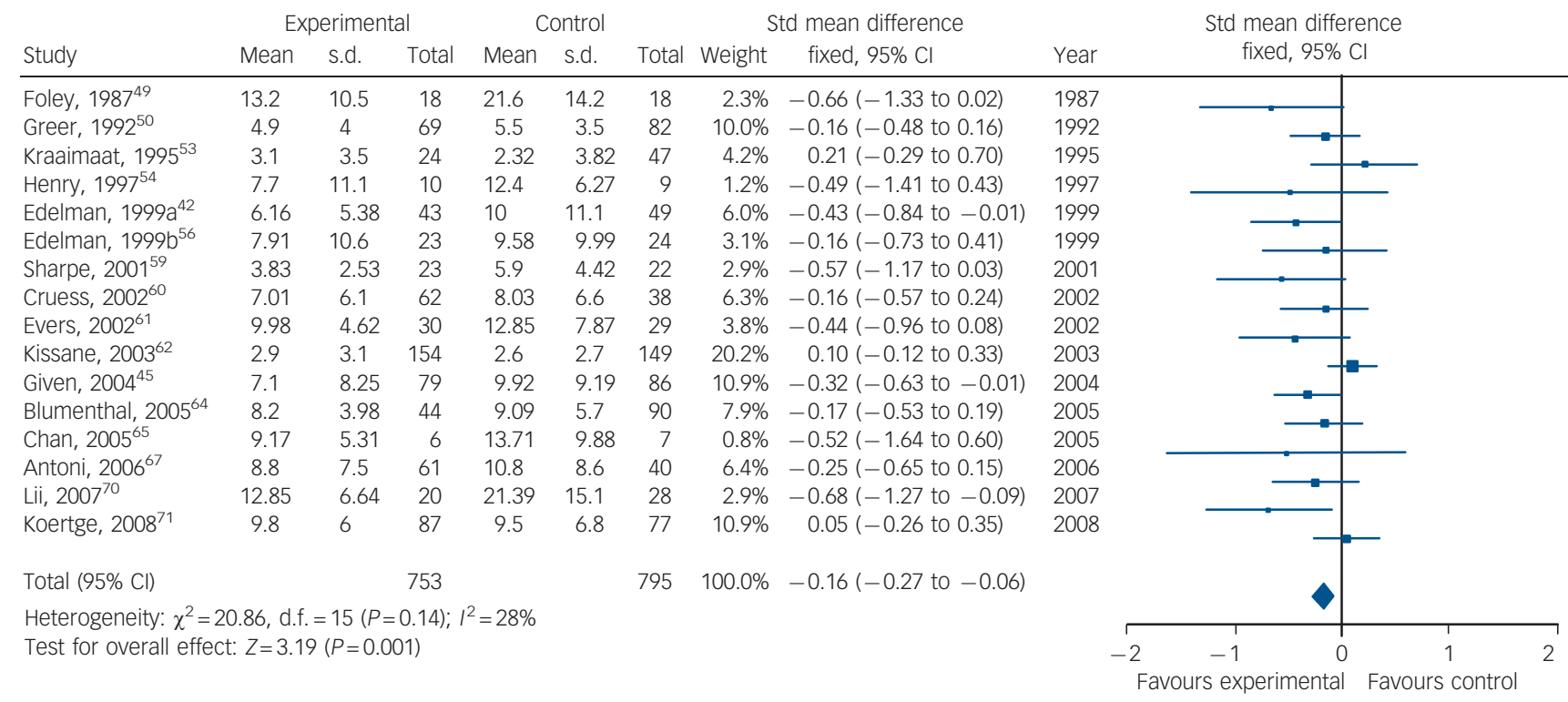

Fig. 3 Forrest plot of standard mean difference (with $95 \% \mathrm{Cl}$ ) of effect of cognitive-behavioural therapy on depressive symptoms in studies of participants with depressive symptoms, with overall effect (black diamond), based on meta-analysis. Std, standard.

\section{Planned subgroup analyses}

Type of CBT

Meta-analyses of studies that applied classic CBT achieved significant overall effects. For studies restricted to participants with depressive disorder, the SMD was -0.34 (95\% CI -0.60 to $-0.09, Z=2.64, P=0.008)$ using a random-effects model and for studies of participants with depressive symptoms the SMD was $-0.31(95 \%$ CI -0.46 to $-0.16, Z=4.10, P<0.001)$.

Two small studies evaluating problem-solving therapy yielded a pooled SMD of -2.86 ( $95 \%$ CI -4.11 to $-1.61, Z=4.49$, $P<0.001)$ based on a total of 172 participants. Five studies evaluating cognitive-behavioural stress management yielded a non-significant SMD of $-0.12(95 \% \mathrm{CI}-0.30$ to 0.05$)$.

\section{Control condition}

Of the studies restricted to participants with depressive disorder, those using a waiting list or a treatment as usual care control condition had a significant pooled effect size of -2.38
$(95 \%$ CI -4.41 to $-0.36, Z=2.31, \quad P=0.02)$ and -0.72 (95\% CI -1.21 to $-0.24, Z=2.94, P=0.003$ ) respectively. A random-effects model was used, because there was considerable heterogeneity. The studies using other psychotherapy as a control group yielded a non-significant pooled SMD of -0.06 ( $95 \% \mathrm{CI}-0.23$ to $0.10, Z=0.76, P=0.45$ ).

For studies of participants with depressive symptoms, only studies comparing CBT with treatment as usual yielded a significant pooled SMD of $-0.28(95 \% \mathrm{CI}-0.41$ to -0.15$)$ in favour of the CBT condition $(Z=4.20, P<0.001)$, whereas no differences were found comparing $\mathrm{CBT}$ versus a waiting-list control condition: $\mathrm{SMD}=-0.13 \quad(95 \% \mathrm{CI}-0.44$ to 0.17 , $Z=0.87, P=0.38$ ); or versus other psychotherapies: $\mathrm{SMD}=0.04$ ( $95 \%$ CI -0.15 to $0.22, Z=0.37, P=0.71$ ).

Treatment delivery in group versus individual format

Only individual treatment delivery led to a significant effect in favour of CBT for both studies of participants with depressive 
disorder and depressive symptoms. The pooled SMD was -0.91 (95 \% CI -1.65 to $-0.17, Z=2.41, P=0.02)$ and $-0.30(95 \%$ CI -0.50 to $-0.11, Z=3.10, P=0.002)$ respectively.

\section{Sensitivity analyses}

Drop-out rate $\geqslant 20 \%$

Sensitivity analyses were performed excluding studies that had a drop-out rate higher or equal to $20 \% .^{42,45,51,55-57,60,67,70-72}$ In the studies restricted to individuals with depressive disorder, the pooled SMD was -1.18 (95\% CI -1.96 to -0.41$)$ in favour of the CBT condition $(Z=2.99, P=0.003)$ using a random-effects model. A non-significant pooled SMD of -0.11 ( $95 \%$ CI -0.25 to $-0.03, Z=1.54, P=0.12$ ) was found in studies of individuals with depressive symptoms.

\section{Intent-to-treat data}

After excluding studies that did not provide intention-to-treat data ${ }^{42,44,45,48-54,56,58-61,63,65-71}$ a non-significant pooled SMD was found of -0.11 (95\% CI -0.31 to $0.09, Z=1.05, P=0.29)$ for studies restricted to individuals with depressive disorder, as well as for the studies of individuals with depressive symptoms: $\mathrm{SMD}=0.03(95 \% \mathrm{CI}-0.16$ to $0.22, Z=0.27, P=0.79)$.

\section{Outcome assessment with a depression subscale}

After excluding studies that only measured depression with a subscale of a (generic) outcome measure, ${ }^{42,50,53,56,57,59,62}$ a significant pooled SMD of $-0.86(95 \%$ CI -1.41 to -0.30$)$ was found in favour of the CBT condition $(Z=3.03, P=0.002)$ in studies of participants with depressive disorder. The studies of participants with depressive symptoms yielded a significant SMD of $-0.25(95 \%$ CI -0.38 to -0.11$)$ in favour of the CBT condition $(Z=3.48, P<0.001)$.

\section{Depressive symptoms as primary or secondary outcome measure}

Excluding the 10 studies with depressive symptoms as a secondary outcome measure, ${ }^{49,50,53,54,59,61,62,64,65,67}$ the pooled SMD was -0.23 (95\% CI -0.39 to $-0.07, Z=2.76, P=0.006$ ).

\section{Discussion}

This meta-analysis of 29 RCTs investigated the effect of CBT on depressive symptoms in 1247 people with a somatic disease and 1338 controls. Our two main meta-analyses of CBT both showed that CBT is effective in treating depressive symptoms in people with a variety of somatic diseases. As expected, the pooled results of studies restricted to individuals with depressive disorder had a stronger significant effect $(-0.83)$ than those including people with depressive symptoms $(-0.16)$. However, the lower the level of depressive symptoms at baseline, the less likely treatment will result in a significant reduction of these symptoms. So, the difference between both meta-analyses may in fact reflect a floor effect.

Reported effect-sizes in meta-analyses of CBT for depressive symptoms or general distress in people with a specific underlying somatic disease are 0.37 for individuals with HIV infection, ${ }^{10}$ 0.36-0.44 for people with cancer, ${ }^{15,74} 0.29$ for those with rheumatoid arthritis, ${ }^{12}$ and 0.31 for those with breast cancer. ${ }^{13}$ The similarity of effect sizes in different populations is suggestive of a general underlying mechanism for depressive symptoms in people with a somatic disease. Coping style might be an important mediating mechanism, ${ }^{75,76}$ as somatically ill individuals with a higher perceived level of control, higher self-efficacy and active coping styles are better adjusted to the somatic illness ${ }^{77,78}$ and are less depressed. ${ }^{78,79}$ The reported effect sizes are all in between our effect sizes of -0.83 for studies including participants with depressive disorder and -0.16 for studies including those with depressive symptoms. Pooling of all studies in our meta-analysis yields a significant overall effect size of -0.49 (data not shown), which is in line with these previous meta-analyses and emphasises the relevance of looking specifically at the definition of depression at baseline.

By performing a comprehensive review and meta-analysis of CBT for the treatment of depressive symptoms in people with a somatic disease, we did not restrict our inclusion criteria to studies which included only individuals with a diagnosis of depression according to the diagnostic criteria of the DSM. In contrast to previous meta-analyses on depressive symptoms in people with a specific somatic disease, we a priori decided to perform separately meta-analyses for studies using predefined criteria for depressive disorder at baseline and those studies including participants with somatic diseases with depressive symptoms in general (in these studies, authors generally assume that a somatic disease is stress-provoking and thus all patients may benefit from CBT).

Furthermore, we included different types of CBT for the following reasons. First, we considered the content of the psychotherapy more important than the name given to it by the study authors. In this paper, CBT was defined as all psychotherapies that included both cognitive restructuring and behavioural activation. Second, we intended to perform a comprehensive review and meta-analysis on this important topic, thereby precluding the emergence of different smaller meta-analyses confined to specific subtypes of CBT. The first subgroup analyses on subtypes of CBT, for instance, might have been published as separate papers. In our opinion nobody would gain by this strategy. Problem-solving therapy is generally seen as a derivative of CBT. ${ }^{80}$ Although we identified only two studies that evaluated problem-solving therapy in this population, the pooled effect size was very large, which may suggest the high value of problem-solving therapy for this particular patient group. In patients with a somatic disease (and thus more handicaps or limitations), the more pragmatic approach of problem-solving therapy may be particularly favourable. Exclusion of these studies would have led to a less informative paper.

Subgroup analyses of CBT versus the different control conditions showed that CBT was superior to treatment as usual as well as a waiting-list control condition. Cognitive-behavioural therapy, however, was not superior to studies using a control condition with another psychological therapy, which consisted mainly of supportive-expressive therapies. Therefore, the effects we found might be caused by non-specific therapeutic effects that are not exclusive for CBT. A recent meta-analysis on the comparison of seven kinds of psychological therapies for depressive disorder in general also found similar effect sizes for the different modalities (CBT, non-directive supportive treatment, behavioural activation treatment, psychodynamic treatment, problem-solving therapy, interpersonal psychotherapy and social skills training). ${ }^{81}$ Interestingly, only individual CBT yielded a significant effect size in studies of both participants with depressive disorder and depressive symptoms. This finding is in contrast with CBT for depression in general. ${ }^{82}$ Individual therapy might be more suitable than group therapy for people with depression with a comorbid somatic disorder. 


\section{Methodological considerations}

The study has some limitations. First, the methodological quality of the included studies was highly variable. The sensitivity analyses showed that the results were partly biased by methodological shortcomings, but the overall conclusions seem valid. For example, exclusion of studies with a drop-out rate of $20 \%$ or more led to an increased effect size in studies restricted to individuals with depressive disorder (from -0.83 to -1.18 ), whereas in studies of participants with depressive symptoms the effect size didn't change very much $(-0.17 v .-0.13)$. Second, analysing only studies providing intent-to-treat data reduced the effect size in the studies of people with depressive disorder from -0.83 to a non-significant -0.11 . This was also the case in studies of people with depressive symptoms. Third, neither exclusion of studies that did not use a specific instrument for assessing depression, nor exclusion of studies that used depressive symptoms as a secondary outcome measure influenced the effect size. In addition to the high variability of the quality, we did find heterogeneity among studies restricted to participants with depressive disorder, caused by three studies with extreme positive results. After removal of these outliers the results remained significant. As a last limitation, we should mention that we could not control for the stage of the underlying disease.

\section{Implications}

Cognitive-behavioural therapy significantly reduces depressive symptoms in people with an underlying somatic disease. The effect size, however, was clearly dependent on the severity of depressive symptoms at the time of inclusion in the study, with less of an effect in individuals with a lower level of depressive symptoms. A significant gap in knowledge, that might contribute to this difference, is the lack of studies that address which components of CBT might be most helpful in this population and by which personality characteristics or coping styles these effects are mediated. Currently, we cannot conclude that the positive effects are specific for CBT-oriented interventions. However, the findings of our meta-analysis support the effectiveness of CBT and therefore as the treatment of choice in people with underlying somatic diseases. The results also suggest that individual treatment might be more effective than group therapy in somatically ill people with depressive disorder. This hypothesis, however, should be further examined in future research. In addition to the need to focus more specifically on which CBT-components are most efficacious, further research should also include long-term follow-up data with respect to both depressive symptoms and the prognosis of the underlying somatic disease.

\section{Matthijs W. Beltman, MSc, Richard C. Oude Voshaar, MD, PhD,}

Anne E. Speckens, MD, PhD, Radboud University Nijmegen Medical Centre,

Department of Psychiatry, Nijmegen, The Netherlands

Correspondence: Matthijs W. Beltman, Radboud University Nijmegen Medical Centre, Department of Psychiatry (966), PO Box 9101, 6500 HB Nijmegen,

The Netherlands. Email: mw.beltman@psy.umcn.nl

First received 13 Feb 2009, final revision 22 Oct 2009, accepted 30 Mar 2010

\section{References}

1 Katon W, Schulberg H. Epidemiology of depression in primary care. Gen Hosp Psychiatry 1992; 14: 237-47.

2 Lustman PJ, Griffith LS, Freedland KE, Kissel SS, Clouse RE. Cognitive behavior therapy for depression in type 2 diabetes mellitus. A randomized, controlled trial. Ann Intern Med 1998; 129: 613-21.
3 Hotopf M, Chidgey J, Addington-Hall J, Ly KL. Depression in advanced disease: a systematic review Part 1. Prevalence and case finding. Palliat Med 2002; 16: 81-97.

4 Saravay SM, Pollack S, Steinberg MD, Weinschel B, Habert M. Four-year follow-up of the influence of psychological comorbidity on medical rehospitalization. Am J Psychiatry 1996; 153: 397-403.

5 Henk HJ, Katzelnick DJ, Kobak KA, Greist JH, Jefferson JW. Medical costs attributed to depression among patients with a history of high medical expenses in a health maintenance organization. Arch Gen Psychiatry 1996; 53: 899-904.

6 Katon W, Sullivan MD. Depression and chronic medical illness. J Clin Psychiatry 1990; 51 (suppl): s3-11.

7 American Psychiatric Association. Practice guideline for the treatment of patients with major depressive disorder (revision). Am J Psychiatry 2000; 157 (suppl): s1-45.

8 Berkman LF, Blumenthal JA, Burg M, Carney RM, Catellier D, Cowan MJ, et al. Effects of treating depression and low perceived social support on clinical events after myocardial infarction: the Enhancing Recovery in Coronary Heart Disease Patients (ENRICHD) Randomized Trial. JAMA 2003; 289: 3106-16.

9 Yohannes AM, Connolly MJ, Baldwin RC. A feasibility study of antidepressant drug therapy in depressed elderly patients with chronic obstructive pulmonary disease. Int J Geriatr Psychiatry 2001; 16: 451-4.

10 Himelhoch S, Medoff DR, Oyeniyi G. Efficacy of group psychotherapy to reduce depressive symptoms among HIV-infected individuals: a systematic review and meta-analysis. Aids Patient Care STDS 2007; 21: 732-9.

11 Dusseldorp E, van Elderen T, Maes S, Meulman J, Kraaij V. A meta-analysis of psychoeducational programs for coronary heart disease patients. Health Psychol 1999; 18: 506-19.

12 Astin JA, Beckner W, Soeken K, Hochberg MC, Berman BM. Psychological interventions for rheumatoid arthritis: a meta-analysis of randomized controlled trials. Arthritis Care Res 2002; 47: 291-302.

13 Tatrow K, Montgomery G. Cognitive behavioral therapy techniques for distress and pain in breast cancer patients: a meta-analysis. J Behav Med 2006; 29: 17-27.

14 Linden W, Phillips MJ, Leclerc J. Psychological treatment of cardiac patients: a meta-analysis. Eur Heart J 2007; 28: 2972-84.

15 Sheard T, Maguire $P$. The effect of psychological interventions on anxiety and depression in cancer patients: results of two meta-analyses. $\mathrm{Br} J$ Cancer 1999; 80: 1770-80.

16 Meyer TJ, Mark MM. Effects of psychosocial interventions with adult cancer patients: a meta-analysis of randomized experiments. Health Psychol 1995; 14: 101-8.

17 National Collaborating Centre for Mental Health. Depression: Management of Depression in Primary and Secondary Care. National Institute for Health and Clinical Excellence, 2007

18 Werkgroep Multidisciplinaire richtlijn Depressie. Multidisciplinaire Richtlijn Depressie [Multidisciplinary Guideline for Depression]. Landelijke Stuurgroep Multidisciplinaire Richtlijnontwikkeling in de GGZ/Trimbos-instituut, 2007 (http://www.ggzrichtlijnen.nl/uploaded/docs/MDR\%20Depressie\%20eerste \%20update\%202010.pdf).

19 American Psychiatric Association. Diagnostic and Statistical Manual of Mental Disorders (4th edn) (DSM-IV). APA, 1994.

20 Deeks JJ. Are You Sure That's a Standard Deviation? (Part 1). Cochrane News, 1997 (http://www.cochrane.org/newslett/ccnewsbi.htm).

21 Deeks JJ. Are You Sure That's a Standard Deviation? (Part 2). Cochrane News, 1997 (http://www.cochrane.org/newslett/ccnewsbi.htm).

22 van Tulder MW, Assendelft WJ, Koes BW, Bouter LM. Method guidelines for systematic reviews in the Cochrane Collaboration Back Review Group for Spinal Disorders. Spine 1997; 22: 2323-30.

23 van Boeijen CA, van Balkom AJLM, van Oppen P, Blankenstein N, Cherpanath A, van Dyck R. Efficacy of self-help manuals for anxiety disorders in primary care: a systematic review. Fam Pract 2005; 22: 192-6.

24 Oude Voshaar RC, Couvée JE, Van Balkom AJLM, Mulder PGH, Zitman FG. Strategies for discontinuing long-term benzodiazepine use. Meta-analysis. Br J Psychiatry 2006; 189: 213-20.

25 Chalmers TC, Smith H, Blackburn B, Silverman B, Schroeder B, Reitman D et al. A method for assessing the quality of a randomized control trial. Control Clin Trials 1981; 2: 31-49.

26 Beck AT, Ward $\mathrm{CH}$, Mendelson $\mathrm{M}$, Mock J, Erbaugh J. An inventory for measuring depression. Arch Gen Psychiatry 1961; 4: 561-71.

27 Beck AT, Steer RA, Brown GK. Beck Depression Inventory (2nd edn): Manual. Psychological Corp, 1996.

28 Hamilton M. A rating scale for depression. J Neurol Neurosurg Psychiatry 1960; 23: 56-62. 
29 Radloff LS. The CES-D Scale: A self-report depression scale for research in the general population. Appl Psychol Meas 1977; 1: 385-401.

30 Zigmond AS, Snaith RP. The hospital anxiety and depression scale. Acta Psychiatr Scand 1983; 67: 361-70.

31 McNair PM, Lorr M, Drappelman L. POMS Manual. Education and Industrial Testing, 1971.

32 Derogatis LR. SCL-90-R Administration, Scoring and Procedures Manual. NSC Pearson, 1994.

33 Huiskes CJAE, Kraaimaat FW, Bijlsma JWJ. Invloed van Reuma op Gezondheid en Leefwijze: Een Zelfbeoordelingslijst voor het Meten van de Invloed van Reuma op Gezondheid en Leefwijze [Impact of Rheumatic Diseases on Health and Lifestyle]. Swets \& Zeitlinger, 1990.

34 Higgins JPT, Green S. Cochrane Handbook for Systematic Reviews of Interventions Version 5.0.2 [updated September 2009]. The Cochrane Collaboration, 2009 (http://www.cochrane-handbook.org).

35 Moher D, Cook DJ, Eastwood S, Olkin I, Rennie D, Stroup DF. Improving the quality of reports of meta-analyses of randomised controlled trials: the QUOROM statement. Lancet 1999; 354: 1896-900.

36 Tan SY, Bruni J. Cognitive-behavior therapy with adult patients with epilepsy: a controlled outcome study. Epilepsia 1986; 27: 225-33.

37 Brown MA, Munford AM, Munford PR. Behavior therapy of psychological distress in patients after myocardial infarction or coronary bypass. J Cardiopulm Rehabil 1993; 13: 201-10.

38 Mulder CL, Emmelkamp PM, Antoni MH, Mulder JW, Sandfort TG, de Vries MJ. Cognitive-behavioral and experiential group psychotherapy for HIV-infected homosexual men: a comparative study. Psychosom Med 1994; 56: 423-31.

39 Parker JC, Smarr KL, Buckelew SP, Stucky-Ropp RC, Hewett JE, Johnson JC, et al. Effects of stress management on clinical outcomes in rheumatoid arthritis. Arthritis Rheum 1995; 38: 1807-18.

40 Moynihan C, Bliss JM, Davidson J, Burchell L, Horwich A. Evaluation of adjuvant psychological therapy in patients with testicular cancer: randomised controlled trial. BMJ 1998; 316: 429-35.

41 Leibing ED, Pfingsten $\mathrm{M}$, Bartmann $\mathrm{U}$, Rueger $\mathrm{U}$, Schuessler $\mathrm{G}$ Cognitive-behavioral treatment in unselected rheumatoid arthritis outpatients. Clin J Pain 1999; 15: 58-66.

42 Edelman S, Bell DR, Kidman AD. A group cognitive behaviour therapy programme with metastatic breast cancer patients. Psychooncology 1999; 8 295-305.

43 Antoni MH, Lehman JM, Kilbourn KM, Boyers AE, Culver JL, Alferi SM, et al. Cognitive-behavioral stress management intervention decreases the prevalence of depression and enhances benefit finding among women under treatment for early-stage breast cancer. Health Psychol 2001; 20: 20-32.

44 Lincoln NB, Flannaghan T. Cognitive behavioral psychotherapy for depression following stroke: a randomized controlled trial. Stroke 2003; 34: 111-5.

45 Given C, Given B, Rahbar M, Jeon S, McCorkle R, Cimprich B, et al. Does a symptom management intervention affect depression among cancer patients: results from a clinical trial. Psychooncology 2004; 13: 818-30.

46 Claesson MM, Birgander LS, Lindahl B, Nasic S, Astrom M, Asplund K, et al. Women's hearts-stress management for women with ischemic heart disease: explanatory analyses of a randomized controlled trial. J Cardiopulm Rehabil 2005; 25: 93-102.

47 Doering LV, Cross R, Vredevoe D, Martínez-Maza O, Cowan MJ. Infection, depression, and immunity in women after coronary artery bypass: a pilot study of cognitive behavioral therapy. Altern Ther Health Med 2007; 13: 18-21.

48 Larcombe NA, Wilson PH. An evaluation of cognitive-behaviour therapy for depression in patients with multiple sclerosis. Br J Psychiatry 1984; 145: 366-71.

49 Foley FW, Bedell JR, LaRocca NG, Scheinberg LC, Reznikoff M. Efficacy of stress-inoculation training in coping with multiple sclerosis. J Consult Clin Psychol 1987; 55: 919-22.

50 Greer S, Moorey S, Baruch JD, Watson M, Robertson BM, Mason A, et al Adjuvant psychological therapy for patients with cancer: a prospective randomised trial. BMJ 1992; 304: 675-80.

51 Kelly JA, Murphy DA, Bahr GR, Kalichman SC, Morgan MG, Stevenson LY, et al. Outcome of cognitive-behavioral and support group brief therapies for depressed, HIV-infected persons. Am J Psychiatry 1993; 150: 1679-86.

52 Evans RL, Connis RT. Comparison of brief group therapies for depressed cancer patients receiving radiation treatment. Public Health Rep 1995; 110 306-11.

53 Kraaimaat FW, Brons MR, Geenen R, Bijlsma JWJ. The effect of cognitive behavior therapy in patients with rheumatoid arthritis. Behav Res Ther 1995; 33: 487-95.
54 Henry JL, Wilson PH, Bruce DG, Chisholm DJ, Rawling PJ. Cognitivebehavioural stress management for patients with non-insulin dependent diabetes mellitus. Psychol Health Med 1997; 2: 109-18.

55 Markowitz JC, Kocsis JH, Fishman B, Spielman LA, Jacobsberg LB, Frances AJ, et al. Treatment of depressive symptoms in human immunodeficiency virus-positive patients. Arch Gen Psychiatry 1998; 55: 452-7.

56 Edelman S, Bell DR, Kidman AD. Group CBT versus supportive therapy with patients who have primary breast cancer. J Cogn Psychother: Int Q 1999; 13 189-202.

57 Mohr DC, Likosky W, Bertagnolli A, Goodkin DE, van der Wende J, Dwyer P, et al. Telephone-administered cognitive-behavioral therapy for the treatment of depressive symptoms in multiple sclerosis. J Consult Clin Psychol 2000; 68: 356-61.

58 Mohr DC, Boudewyn AC, Goodkin DE, Bostrom A, Epstein L. Comparative outcomes for individual cognitive-behavior therapy, supportive-expressive group psychotherapy, and sertraline for the treatment of depression in multiple sclerosis. J Consult Clin Psychol 2001; 69: 942-9.

59 Sharpe L, Sensky T, Timberlake N, Ryan B, Brewin CR, Allard S. A blind, randomized, controlled trial of cognitive-behavioural intervention for patients with recent onset rheumatoid arthritis: preventing psychological and physical morbidity. Pain 2001; 89: 275-83.

60 Cruess S, Antoni MH, Hayes A, Penedo F, Ironson G, Fletcher MA, et al. Changes in mood and depressive symptoms and related change processes during cognitive-behavioral stress management in HIV-infected men. Cognit Ther Res 2002; 26: 373-92.

61 Evers AWM, Kraaimaat FW, van Riel PLCM, de Jong AJL. Tailored cognitivebehavioral therapy in early rheumatoid arthritis for patients at risk: a randomized controlled trial. Pain 2002; 100: 141-53.

62 Kissane DW, Bloch S, Smith GC, Miach P, Clarke DM, Ikin J, et al. Cognitiveexistential group psychotherapy for women with primary breast cancer: a randomised controlled trial. Psychooncology 2003; 12: 532-46.

63 Nezu AM, Nezu CM, Felgoise SH, McClure KS, Houts PS. Project Genesis: assessing the efficacy of problem-solving therapy for distressed adult cancer patients. J Consult Clin Psychol 2003; 71: 1036-48.

64 Blumenthal JA, Sherwood A, Babyak MA, Watkins LL, Waugh R, Georgiades A, et al. Effects of exercise and stress management training on markers of cardiovascular risk in patients with ischemic heart disease: a randomized controlled trial. JAMA 2005; 293: 1626-34.

65 Chan I, Kong P, Leung P, Au A, Li P, Chung R, et al. Cognitive-behavioral group program for Chinese heterosexual HIV-infected men in Hong Kong. Patient Educ Couns 2005; 56: 78-84.

66 Mohr DC, Hart SL, Julian L, Catledge C, Honos-Webb L, Vella L, et al. Telephone-administered psychotherapy for depression. Arch Gen Psychiatry 2005; 62: 1007-14.

67 Antoni MH, Carrico AW, Duran RE, Spitzer S, Penedo F, Ironson G, et al. Randomized clinical trial of cognitive behavioral stress management on human immunodeficiency virus viral load in gay men treated with highly active antiretroviral therapy. Psychosom Med 2006; 68: 143-51.

68 Savard J, Simard S, Giguère I, Ivers H, Morin CM, Maunsell E, et al. Randomized clinical trial on cognitive therapy for depression in women with metastatic breast cancer: psychological and immunological effects. Palliat Support Care 2006; 4: 219-37.

69 Gellis ZD, McGinty J, Horowitz A, Bruce ML, Misener E. Problem-solving therapy for late-life depression in home care: a randomized field trial. Am J Geriatr Psychiatry 2007; 15: 968-78.

70 Lii YC, Tsay SL, Wang TJ. Group intervention to improve quality of life in haemodialysis patients. J Clin Nurs 2007; 16: 268-75.

71 Koertge J, Janszky I, Sundin Ö, Blom M, Georgiades A, László KD, et al. Effects of a stress management program on vital exhaustion and depression in women with coronary heart disease: a randomized controlled intervention study. J Intern Med 2008; 263: 281-93.

72 Kunik ME, Veazy C, Cully JA, Souchek J, Graham DP, Hopko D, et al. COPD education and cognitive behavioral therapy group treatment for clinically significant symptoms of depression and anxiety in COPD patients: a randomized controlled trial. Psychol Med 2008; 38: 385-96.

73 Safren SA, O'Cleirig C, Tan J, Raminani S, Reilly LC, Otto MW, et al. A randomized controlled trial of cognitive behavioral therapy for adherence and depression (CBT-AD) in HIV-infected individuals. Health Psychol 2009; 28: $1-10$.

74 Akechi T, Okuyama T, Onishi J, Morita T, Furukawa TA. Psychotherapy for depression among incurable cancer patients. Cochrane Database Syst Rev 2008; 2: CD005537.

75 Caplette-Gingras A, Savard J. Depression in women with metastatic breast cancer: a review of the literature. Palliat Support Care 2008; 6: 377-87.

76 MacMahon KMA, Lip GYH. Psychological factors in heart failure: a review of the literature. Arch Intern Med 2002; 162: 509-16. 
77 Dunkel-Schetter C, Feinstein LG, Taylor SE, Falke RL. Patterns of coping with cancer. Health Psychol 1992; 11: 79-87.

78 Hirai K, Suzuki Y, Tsuneto S, Ikenega M, Hosaka T, Kashiwagi T. A structural model of the relationships among self-efficacy, psychological adjustment, and physical condition in Japanese advanced cancer patients. Psychooncology 2002; 11: 221-9.

79 Ranchor AV, Sanderman R, Steptoe A, Wardle J, Miedema I, Ormel J. Pre-morbid predictors of psychological adjustment to cancer. Qual Life Res 2002; 11: 101-13.
80 Hawton K, Kirk J. Problem-solving. In Cognitive Behaviour Therapy for Psychiatric Problems: A Practial Guide (eds K Hawton, PM Salkovskis, J Kirk, DM Clark): 406-26. Oxford University Press, 1989.

81 Cuijpers P, van Straten A, Andersson G, van Oppen P. Psychotherapy for depression in adults: a meta-analysis of comparative outcome studies. J Consult Clin Psychol 2008; 76: 909-22.

82 McDermut W, Miller IW, Brown RA. The efficacy of group psychotherapy for depression: a meta-analysis and review of the empirical research. Clin Psychol Sci Pract 2001; 8: 98-116.

\section{fallen \\ Mark Lombardi}

\section{Raymond Cavanaugh Jr}

Mark Lombardi was born in 1951 in upstate New York. While studying art history at nearby Syracuse University, he became involved with a collaborative effort on a multimedia collage, 'Teapot Dome to Watergate'. This work drew on high-ranking government corruption, particularly the infamous Watergate scandal of then-president Richard Nixon.

Lombardi's contributions impressed a prominent museum director who offered him a post-grad job as curator at the Contemporary Arts Museum in Houston, Texas. There, Lombardi stayed for 2 years before becoming a reference librarian. Such work compelled him to collect and categorise massive amounts of information; these tasks would influence his later creations.

During the 1980s, Lombardi produced abstract paintings, got married, and established an art gallery, which proved a short-lived endeavour. By the ensuing decade, he had returned to the theme of his undergraduate multimedia project and was conducting research on the prominent corporate scandals of the time.

Striving to understand the complexities of these scandals, Lombardi made countless notes, starting a process of index cards - to outlines - to diagrams featuring 'spider webs of illustrations'. These diagrams, while aiming to achieve an aesthetic effect, also attempted to 'document financial and political frauds by power brokers'

One such work, 'George W. Bush, Harken Energy and Jackson Stephens, ca 1979-90', explored certain Texas business deals and displayed a supposed link between the Bush and bin Laden families. In other works, called 'narrative structures', Lombardi even ventured to place high-ranking mobsters and intelligence officials in his diagrammed criminal conspiracies.

For years, Lombardi had lingered in almost total obscurity as an abstract painter. Now, with these controversial diagrams, his career found some trajectory. His work was the sole subject of a successful New York City art show in November 1998. In February 2000, the diagrams received further acclaim at a second exhibition.

On 22 March 2000, Lombardi's lifeless body was found hanging in his Brooklyn apartment. Friends of the artist were stunned that he would die by suicide while 'at the top of his game'. Considering his subversive subject matter, there was speculation of foul play. A current internet search of 'Mark Lombardi - suicide' yields some people who feel that the artist's death was not his depressive volition, but that he was, in fact, 'suicided'.

The medical examiner, however, declared that Lombardi had, indeed, killed himself. Lombardi had been described as 'manic' and would, at times, speak of 'deep depressions'; he would also sometimes evince isolating tendencies.

Ensuing media coverage depicted Lombardi's demise as the result of a bipolar disorder brought on by the pressures of approaching stardom, as well as the stress he encountered when one of his foremost works was destroyed by an indoor sprinkler.

Three years after his death, the 25-drawing exhibit 'Mark Lombardi: Global Networks' commenced a museum tour. 